University of Wollongong

Research Online

Faculty of Engineering and Information

Faculty of Engineering and Information

Sciences - Papers: Part A

Sciences

$1-1-2016$

\title{
Mechanical properties and tribological behavior of aluminum matrix composites reinforced with in-situ AIB2 particles
}

\author{
Linlin Yuan \\ University of Science And Technology Beijing \\ Jingtao Han \\ University of Science and Technology of China, University of Science And Technology Beijing, \\ hanjt@ustb.edu.cn \\ Jing Liu \\ University of Science and Technology of China \\ Zhengyi Jiang \\ University of Wollongong, jiang@uow.edu.au
}

Follow this and additional works at: https://ro.uow.edu.au/eispapers

Part of the Engineering Commons, and the Science and Technology Studies Commons

Research Online is the open access institutional repository for the University of Wollongong. For further information contact the UOW Library: research-pubs@uow.edu.au 


\title{
Mechanical properties and tribological behavior of aluminum matrix composites reinforced with in-situ AlB2 particles
}

\author{
Abstract \\ Aluminum matrix composites (AMCs) reinforced with in-situ $\mathrm{AlB}_{2}$ particles have been fabricated using a \\ combination of powder metallurgy, hot rolling and solution treatment. The effects of boron content ( 7 and \\ $12 \mathrm{wt} \%$ ), hot rolling and heat treatment parameters on the microstructures and mechanical properties of \\ the composites were investigated by means of scanning electron microscopy (SEM), tensile test and \\ micro-hardness measurements. The friction coefficient, wear behavior and scratch morphology of the \\ AMCs and pure aluminum were also studied using scratch tests. The hardness and wear properties are \\ higher in a case of composites when compared to unreinforced matrix material.

\section{Keywords} \\ situ, tribological, reinforced, behavior, composites, matrix, aluminum, particles, mechanical, alb2, \\ properties \\ Disciplines \\ Engineering | Science and Technology Studies

\section{Publication Details} \\ Yuan, L., Han, J., Liu, J. \& Jiang, Z. (2016). Mechanical properties and tribological behavior of aluminum \\ matrix composites reinforced with in-situ AlB2 particles. Tribology International, 98 41-47.
}


Mechanical properties and tribological behavior of aluminum matrix composites reinforced with in-situ AlB2 particles

Linlin Yuana, Jingtao Hana, ${ }^{*}$, Jing Liua, Zhengyi Jiangb

aSchool of Materials Science and Engineering, University of Science and Technology Beijing, Beijing, 100083, China

bSchool of Mechanical, Materials and Mechatronic Engineering, University of Wollongong, 2500, Australia

Abstract: Aluminum matrix composites (AMCs) reinforced with in-situ AlB2 particles have been fabricated using a combination of powder metallurgy, hot rolling and solution treatment. The effects of boron content ( 7 and $12 \mathrm{wt} . \%$ ), hot rolling and heat treatment parameters on the microstructures and mechanical properties of the composites were investigated by means of scanning electron microscopy (SEM), tensile test and micro-hardness measurements. The friction coefficient, wear behavior and scratch morphology of the AMCs and pure aluminum were also studied using scratch tests. The hardness and wear properties are higher in a case of composites when compared to unreinforced matrix material.

Keywords: Aluminum matrix composites, AlB2 reinforcement, Powder metallurgy, Wear *Corresponding author. E-mail address: hanjt@ustb.edu.cn(Jingtao Han)

\section{Introduction}

Aluminum matrix composites(AMCs) reinforced with ceramic particles have been extensively used in the aircraft, aerospace and automotive industries because of their high stiffness, strength to weight ratio, low coefficient of thermal expansion and good wear resistance [1-3]. The particulate reinforcements most often added to the pure aluminum or alloys include SiC, $\mathrm{SiO} 2, \mathrm{~B} 4 \mathrm{C}, \mathrm{TiB} 2$ and Al2O3 [4-9]. In previous studies, Khorshid et al. prepared the AMCs reinforced by two sizes of alumina particles by wet attrition milling and hot forward extrusion processes [10]. Haghighi et al. consolidated Al-5 vol.\% nano-Al2O3 by equal channel angular pressing and extrusion and compared the physical and mechanical properties [11]. Vajargah et al. fabricated Al/TiB2 nano composites via powder metallurgy route through a primarily cold isostatic pressing of aluminum powder containing different TiB2 volume ratio and subsequent sintering at $650^{\circ} \mathrm{C}$ and $680^{\circ} \mathrm{C}[12]$.

Among all the reinforcements, boride particles are often chosen because of their lower density and the fact that their hardness is similar to other particles. Researchers reported that boride particulate reinforced AMCs can be fabricated via various processing techniques such as liquid state method, semisolid state method and powder metallurgy [13-16]. Toptan et al. produced AA1070 and AA6063 matrix B4Cp reinforced composites by using titanium containing flux (K2TiF6) in order to overcome the poor wetting ability associated with the conventional casting [17]. Mazahery et al. worked on processing of Al-Si matrix composites reinforced with TiB2 coated B4C particulates and studied the wear behavior of the sol-gel coated B4C particulate reinforced A356 matrix composites [14]. Topcu et al. prepared Al matrix composites reinforced with different B4C ratios by powder metallurgy and investigated the mechanical properties of the composites [18]. Moreover, spark plasma sintering (SPS) method has been developed for sintering advanced ceramics and composite materials because SPS process allows preparation of bulk materials from mechanical alloyed powders using shorter sintering time at lower temperatures compared to hot 
pressing and hot isostatic press processes [15]. In addition, the plasma generated between particles contributes to the elimination of surface impurities, leading to enhanced sintering and consolidation [19].

Unlike the many studies which have been done of the mechanical properties and structural characterization of B4C reinforced AMCs [14-18,20-27], little research has been done to examine the wear properties of AIB2 particle reinforced AMCs [28-31]. Actually, AlB2 particles are effective nucleation sites for aluminum alloys and the chemical reactivity between particles and melt is minimized, leading to excellent interfacial bonding with the matrix [32].

In the present work, AMCs reinforced with in-situ AIB2 particles are processed using powder metallurgy (mechanical alloying followed by spark plasma sintering) and hot rolling, the mechanical and wear properties of these particle-reinforced composites are investigated.

\section{Experimental procedure}

\subsection{Fabrication of in-situ composites}

The AMCs containing 7 and $12 \mathrm{wt} \%$ boron powders were prepared using the powder metallurgy (PM) process and marked as $\mathrm{Al}-7 \mathrm{wt} \% \mathrm{~B}$ and $\mathrm{Al}-12 \mathrm{wt} \% \mathrm{~B}$. The gas atomized aluminum powders (General Research Institute for Nonferrous Metals, 99.9\% purity, 90um average particle size) were blended with crystalline boron powders with equiaxial microstructure of average size $75 \mu \mathrm{m}$ (measured by LMS-30 laser particle size analyzer) in a high-energy ball mill for 5 minutes. The dry-milling method was used in this process. The parameters of ball milling were: ball to powder weight ratio: 10:1; ball material: AISI 420 stainless steel; ball diameter: $6 \mathrm{~mm}$; speed: $1000 \mathrm{rpm}$. $0.5 \mathrm{wt} \%$ stearic acid powders were added into each batch to inhibit adhesion between the powder particles. Argon gas (99.9\% purity) was put into a steel jar as protection because Al and B powders oxidize quickly in contact with oxygen. The powder mixtures were naturally air dried after milling.

The powder mixtures were sintered by spark plasma sintering (SPS) at $550^{\circ} \mathrm{C}$ at a heating rate of 40/min under a pressure of 50MPa (Dr.Sinter SPS-1050, Japan). The sintered samples were disks with $35 \mathrm{~mm}$ diameter and $4 \mathrm{~mm}$ height. The theoretical densities of the compacts were calculated from rule of mixtures given as Eq. 1 [33]:

$\rho_{\text {theor }}=\rho_{1} f_{1}+\rho_{2} f_{2}+\rho_{2} f_{3}$

where $\mathrm{f} 1, \mathrm{f} 2$ and $\mathrm{f} 3$ are the volume percentage of the boron, aluminum and AlB2, respectively, $\mathrm{p} 1$ is the density of the boron $(=2.34 \mathrm{~g} / \mathrm{cm} 3)$ [34], $\rho 2$ is the density of the aluminum $(=2.7 \mathrm{~g} / \mathrm{cm} 3)$ [35], and $\rho 3$ is the density of the AlB2 $(=3.19 \mathrm{~g} / \mathrm{cm} 3)$ [33]. The volume percentage of each phase was determined using ImagePro Plus software (Media Cybernetics). The actual densities of samples were determined using the Archimedes method.

The disks were heated to $450^{\circ} \mathrm{C}$ for $30 \mathrm{~min}$ in an electric furnace chamber, hot-rolled at $400-450^{\circ} \mathrm{C}$ with each pass reduction of $10-15 \%$ and the finishing thickness was $2 \mathrm{~mm}$. The hot-rolled plates were maintained at $450^{\circ} \mathrm{C}$ for $2 \mathrm{~h}$, and then water-quenched to room temperature.

$\mathrm{X}$-ray diffraction (XRD) investigations of the sintered, hot-rolled and heat treated samples were

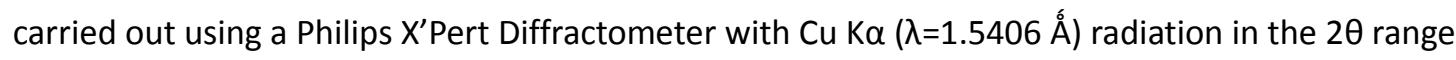
of $20-100^{\circ}$ at a rate of $4^{\circ} / \mathrm{min}$.

The microstructures of the samples were observed using a scanning electron microscope (SEM) 
equipped with an energy dispersive spectrometer (EDS, ZEISS ULTRA 55) and a 3D laser scanning microscope (VK-X100/X200 Series).

2.2 Uniaxial tensile and hardness tests

All specimens were polished before the tests using a polishing machine (Struers, TegraPol-21+TegraForce-5). The tensile tests were carried out using a universal testing machine (CMT4105) to investigate the tensile properties of the composites in the heat treated condition. Three specimens were used for each test and the average value was taken into account.

The micro-hardness of both pure Al and composites was measured using aLEICA-VMHT-30M Vickers tester with $100 \mathrm{gf}$ load.

\subsection{Scratch test}

The scratch tests were performed at room temperature using a Revetest scratch tester (CSM Instruments). The surface roughness of samples was measured to be about $0.05 \mu \mathrm{m}$. In the present work, single-passed scratches were made using a diamond indenter with a spherical tip radius of $200 \mu \mathrm{m}$. Normal load from $0.1 \mathrm{~N}$ to $30 \mathrm{~N}$ was applied progressively with a scratch length of $3 \mathrm{~mm}$. The scratch tests were carried out at two different sliding velocities, that is, 15 and $45 \mathrm{~mm} / \mathrm{min}$. Frictional force was measured during the scratch tests and the friction coefficient is calculated by $\mu=\mathrm{Ft} / \mathrm{Fn}$, where $\mathrm{Ft}$ is the tangential force and $\mathrm{Fn}$ is the applied normal load of the indenter. The wear surfaces were observed under a 3D laser scanning microscope in order to analyze the wear mechanism and the wear area below the original surface was measured using a tactile profilometer.

The pure aluminum samples were prepared by casting and forging aluminum (the raw materials for atomized aluminum powders).

\section{Results and discussion}

Fig.1 shows the SEM photographs of the horizontal cross sections for binary Al-7wt\%B and Al-12wt\%B composites (sintered, hot rolled and heat treated, respectively). Multilayer composite structures were observed. According to the EDS results, as given in Fig. 2, it can be inferred that the ribbons embedded in the aluminum matrix are the agglomerations of boron and/or borides (see the mark in Fig. 1(a) and 1(d)). It is shown that the increase in boron content enhances the possibility of agglomerations, because the excess boron powder cannot mix sufficiently in a shorter time. To identify the phases of the composites, XRD investigations were conducted. Fig. 3 illustrates the XRD patterns of the composites under different conditions. Comparing experimental values with the standard values obtained from JCPDS card (PDF no. was marked in Fig. 3), the presences of Al, B and AlB2 were detected. A certain amount of Fe contamination was also detected arising from the milling jar and balls. It is worth noting that the intensity of reflection peak around $2 \theta=28^{\circ}$ increases after hot rolling and heat treatment for $\mathrm{Al}-7 \mathrm{wt} \% \mathrm{~B}$ composites, but no obvious change is found for $\mathrm{Al}-12 \mathrm{wt} \% \mathrm{~B}$ composites. According to the previous study, the peak heights can be used instead of integrated intensities when the percentage of each phase is calculated. The peak intensity ratio is proportional to the molar fraction ratio of the substances in a mixture [36]. It can be concluded that a slight formation of the AlB2 phase takes place during hot rolling and heat treatment for Al-7wt\%B composites. During the sintering process, some parts of the boron powders reacted with aluminum in-situ forming AlB2 particles, and a particle reinforced Al matrix structure was generated. The lamellar AlB2 particles are 
around $5 \mu \mathrm{m}$ in length. The white dendrites of aluminum and dark AlB2 flakes (arrows in Fig. 1) were distributed in the Al matrix. It shows a good interface bonding between AlB2 particles and Al matrix. Some voids or porosity were observed in the sintered samples (the black spots in Fig. $1 \mathrm{a}$ and $1 \mathrm{~d}$ ), leading to low mechanical properties of the materials. After hot rolling, a majority of the AIB2 particles showed a hexagonal morphology and became more uniform compared to that of sintered samples, as shown in Fig. 1(b) and (e). It can be seen that the distribution of the thickness of boron/boride layers is reduced and the internal voids are eliminated. This means that hot rolling can help to reduce the porosity and optimize the reinforcement distribution, as has been shown in previous research [37]. It is also stated that the flow of the aluminum matrix around the AlB2 under high pressure can improve the bonding strength of AlB2 and matrix.

The AlB2 particles can be seen to be coarser in both composites during heat treatment, as shown in Fig. 1(c) and (f). Fig. 1(c) reveals a uniform distribution of AlB2 particles and lower agglomeration compared to Fig. 1(f). The figures also clearly show that a higher content of boron powder does not lead to a higher reinforcement volume. This is primarily attributed to the agglomeration of the boron particles in the structure which reduces the real reinforcement in the matrix [38]. The observation of microstructure is consistent with the XRD results, as shown in Fig. 3.
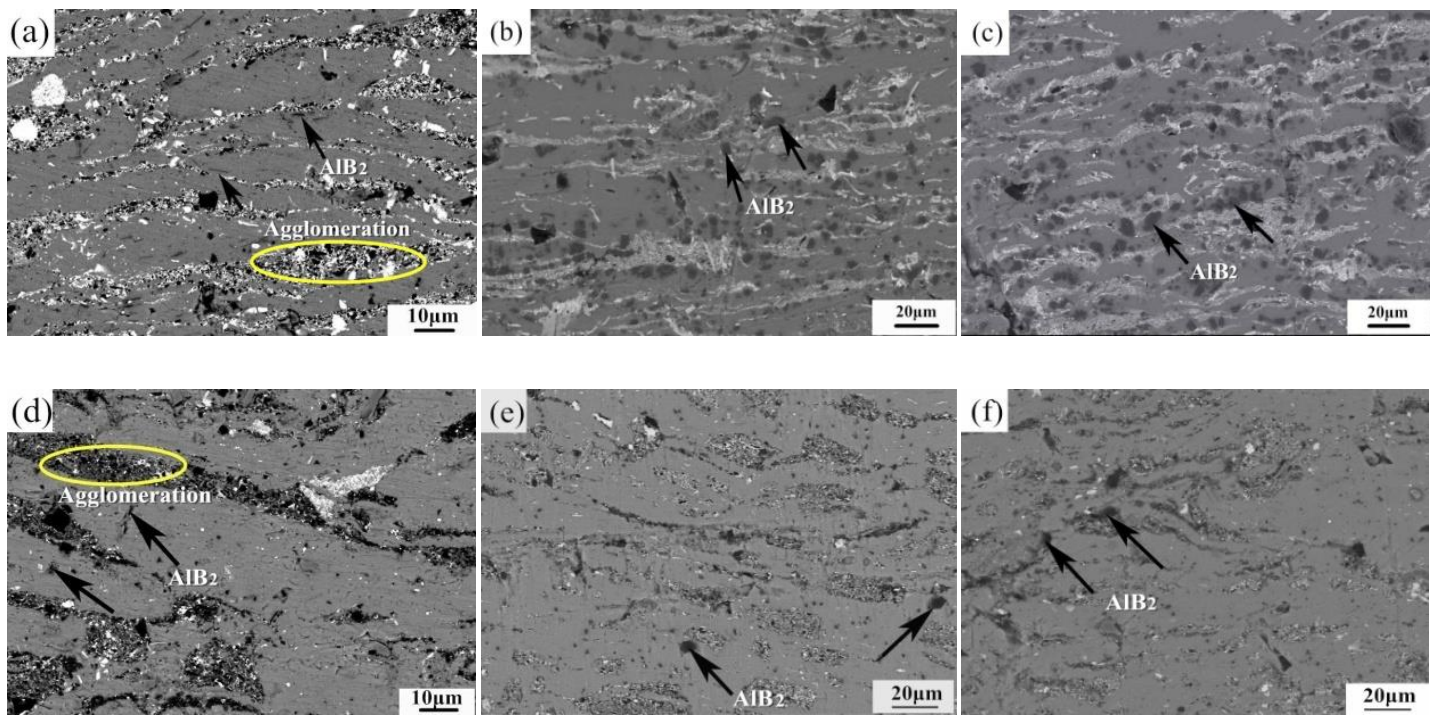

Fig. 1 SEM micrographs of composites (a) Sintered Al-7wt\%B, (b) hot rolled Al-7wt\%B, (c) heat treated $\mathrm{Al}-7 \mathrm{wt} \% \mathrm{~B}$, (d) sintered $\mathrm{Al}-12 \mathrm{wt} \% \mathrm{~B}$, (e) hot rolled $\mathrm{Al}-12 \mathrm{wt} \% \mathrm{~B}$, and (f) heat treated Al-12wt\%B.
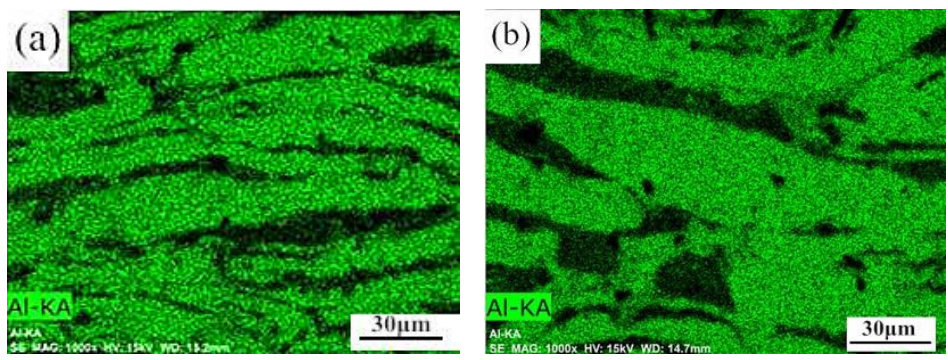

Fig. 2 EDS analysis results of composites (a) Sintered Al-7wt\%B and (b) sintered Al-12wt\%B. 

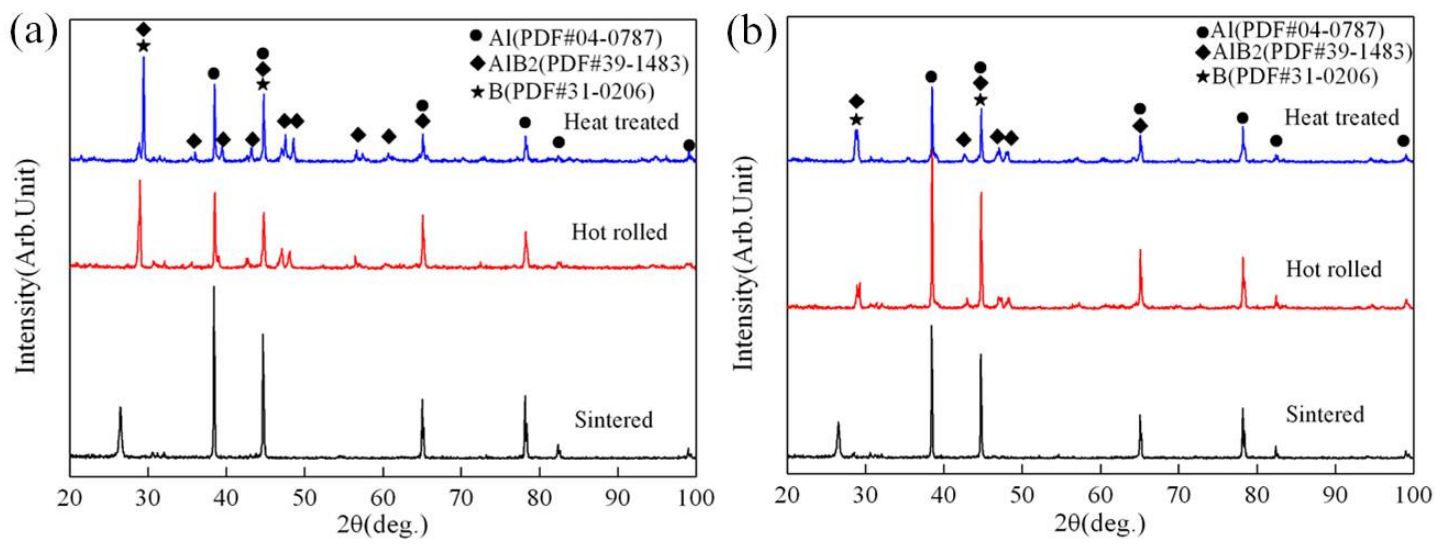

Fig. 3 XRD patterns of the composites (a) Al-7wt\%B specimens and (b) Al-12wt\%B specimens.

The density values of the sintered compacts are shown in Table 1. The Al-12wt\%B sample has higher relative density than that of the Al-7wt\%B sample. In general, the sinterability of $\mathrm{Al}$ powders is relatively low due to the strong oxide scale on the surface of Al powders which prevents direct contact between the particles [39]. In the present study, the oxygen content was reduced by the SPS process as shown in Table 1. The specific surface cleaning effect of the SPS and high load pressure improved the contact between the particles by breaking the oxide scale on the surface of the particles.

Table 1 Some properties of the pure Al and composites

\begin{tabular}{llll}
\hline Sample & Density g/cm3 & Relative density/\% & Oxygen content/\% \\
\hline Pure Al & 2.583 & 95.66 & - \\
Al-7wt\%B powder & - & - & 1.92 \\
Al-7wt\%B compact & 2.268 & 85.29 & 1.47 \\
$\begin{array}{l}\text { Al-12wt\%B } \\
\text { powder }\end{array}$ & - & - & 1.79 \\
$\begin{array}{l}\text { Al-12wt\%B } \\
\text { compact }\end{array}$ & 2.261 & 85.31 & \\
\hline
\end{tabular}

The mechanical properties of the pure Al and the composites investigated are presented in Table 2. Each test was done three times and the average value is reported. Compared with the matrix material, the tensile and yield strengths of the Al-7wt\%B composite increase significantly, whereas the elongation decreases. The Al- $12 \mathrm{wt} \% \mathrm{~B}$ specimens, however, exhibit lower tensile strength and elongation than those of the unreinforced material. It can be concluded that the excessive addition of boron powders in the matrix enhances the possibility of agglomeration, leading to poor performance of the composite. As can be clearly seen in Table 2, both the tensile and yield strengths of hot rolled composites are higher than the sintered composites. This is because that the large deformation improves the bonding strength between particles and matrix and allows the load to effectively transfer by AlB2/Al interface. Furthermore, the composites with heat treatment exhibit the highest strength. Basically, the changing trend of elongation is opposite to that of strength.

Table 2 Tensile properties of the pure Al and composites

\begin{tabular}{lllll}
\hline Samples & $\begin{array}{l}\text { Tensile } \\
(\mathrm{MPa})\end{array}$ & strength & Yield strength (MPa) & Elongation (\%) \\
\hline
\end{tabular}




\begin{tabular}{llll}
\hline Pure Al & $55.8 \pm 2.1$ & $15.6 \pm 2.2$ & $24.3 \pm 0.9$ \\
Sintered Al-7wt\%B & $79.6 \pm 3.8$ & $32.5 \pm 2.6$ & $7.8 \pm 0.6$ \\
Rolled Al-7wt\%B & $99.9 \pm 3.2$ & $60.6 \pm 3.0$ & $6.7 \pm 0.7$ \\
Heat treated Al-7wt\%B & $145.7 \pm 4.1$ & $99.4 \pm 3.9$ & $3.7 \pm 0.8$ \\
Sintered Al-12wt\%B & $36.4 \pm 2.7$ & $18.5 \pm 2.3$ & $9.3 \pm 0.6$ \\
Rolled Al-12wt\%B & $41.6 \pm 2.4$ & $24.7 \pm 2.0$ & $11.1 \pm 0.7$ \\
Heat treated & $47.4 \pm 2.3$ & $31.2 \pm 2.6$ & $8.4 \pm 0.8$ \\
Al-12wt\%B & & & \\
\hline
\end{tabular}

The average micro-hardness values for the sintered, hot-rolled and heat treated composite samples were obtained, as shown in Fig.4. It can be seen that the AlB2 particles enhance the hardness of the virgin aluminum sample (20.5HV in this study). This is due to the fact that the stiffer and harderAIB2 reinforcement increases the constraint to plastic activity of the soft matrix during the hardness test. The hardness of the hot-rolled and heat treated samples also drops down gradually when compared to sintered samples.

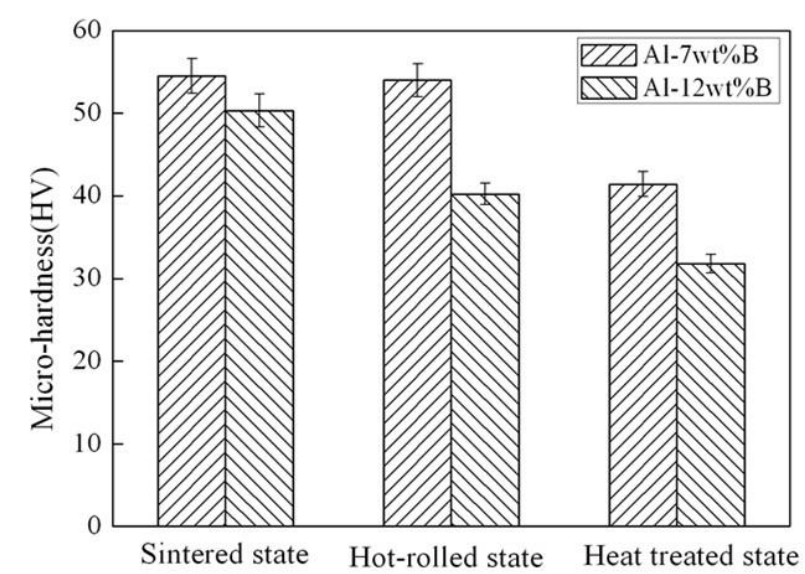

Fig. 4 Vickers hardness with 100gf load for the composites under different conditions.

It is known that plastic deformation leads to work hardening for most polycrystalline metals but the stress can be relaxed when the strain increases to a certain extent. The strain softening occurs during hot working because of the dynamic recovery and dynamic recrystallisation $[40,41]$. As the stack fault energy of aluminum matrix is higher, the dislocations can be easier to move in the form of cross slip, making opposite dislocations eliminated. The dislocations can dynamically recover during the movement. In this case, the softening rate is higher than hardening rate, resulting in work softening. Accordingly, this softening counteracts work hardening. The interplay gradually decreases the work-hardening rate. A decrease in the hardness of the composites after heat treatment can be seen. In this study, the reduced hardness of the composites after hot rolling is ascribed to the higher strain softening rate because the grain coarsening during heat treatment decreases the role of grain refinement and the solid solution hardening is limited because of the low solubility of $\mathrm{B}$ in $\mathrm{Al}\left(0.022 \mathrm{wt} \%\right.$ at $659.7^{\circ} \mathrm{C}$ [42]). It is clear that the hardness of Al- $7 \mathrm{wt} \% \mathrm{~B}$ composites is higher than that of $\mathrm{Al}-12 \mathrm{wt} \% \mathrm{~B}$. This is because of the larger number of AlB2 particles contained in Al-7wt\%B samples. 

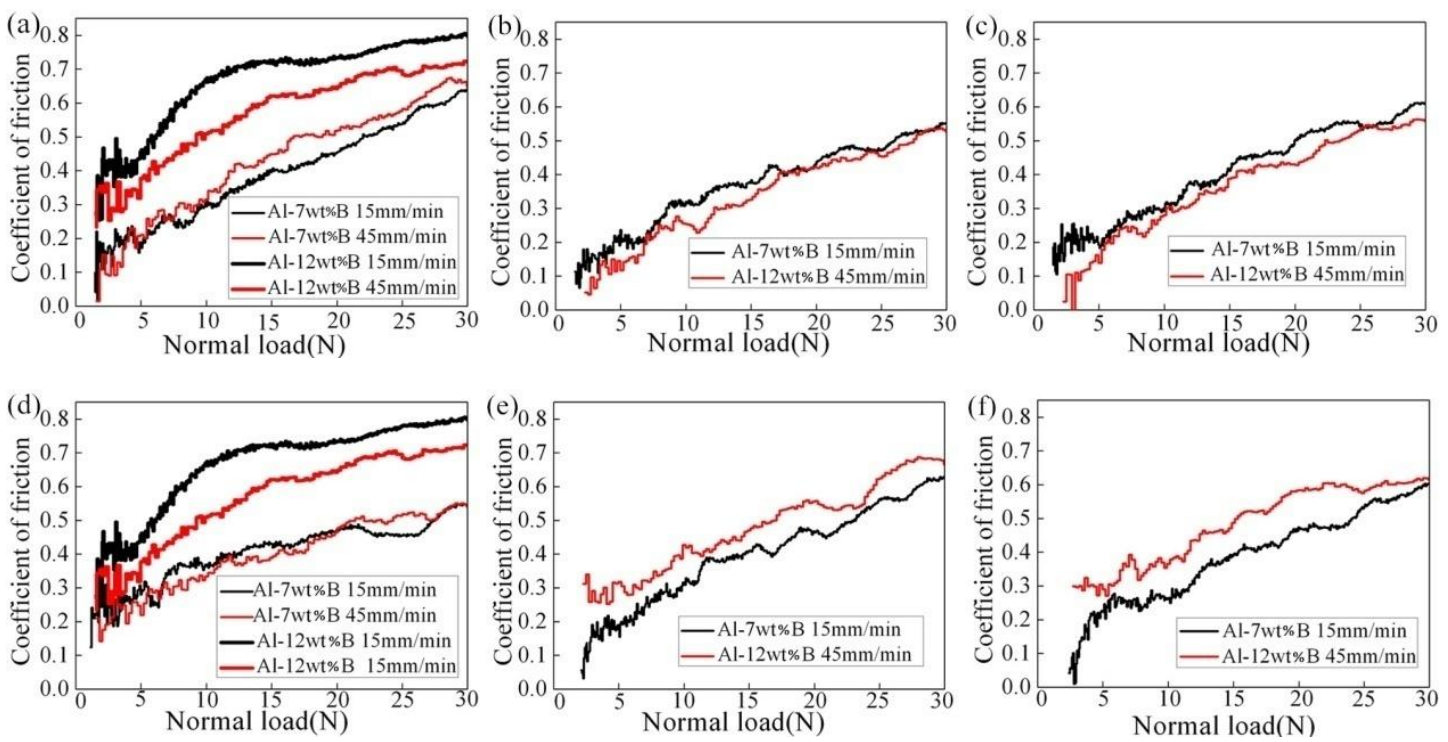

Fig. 5 Coefficient of friction as a function of the applied normal force for all materials (a) Sintered Al-7wt\%B compared with pure $\mathrm{Al}$, (b) hot rolled $\mathrm{Al}-7 \mathrm{wt} \% \mathrm{~B}$, (c) heat treated $\mathrm{Al}-7 \mathrm{wt} \% \mathrm{~B}$, (d) sintered Al-12wt\%B compared with pure Al, (e) hot rolledAl-12wt\%B, and (f) heat treated Al-12wt\%B

Fig. 5 shows the evolution of the coefficient of friction as a function of the progressive normal load for all samples. The coefficient of friction $\mu$ increases almost linearly with the load in all cases. This suggests that the reinforcements embedded in the matrix lead to a lower coefficient of friction, as shown in Fig. 5(a) and (d). It can also be seen that sliding speed has a little effect on the coefficient of friction. The results indicate, however, that the influence of speed is inconsistent with the coefficient of friction.

(a)

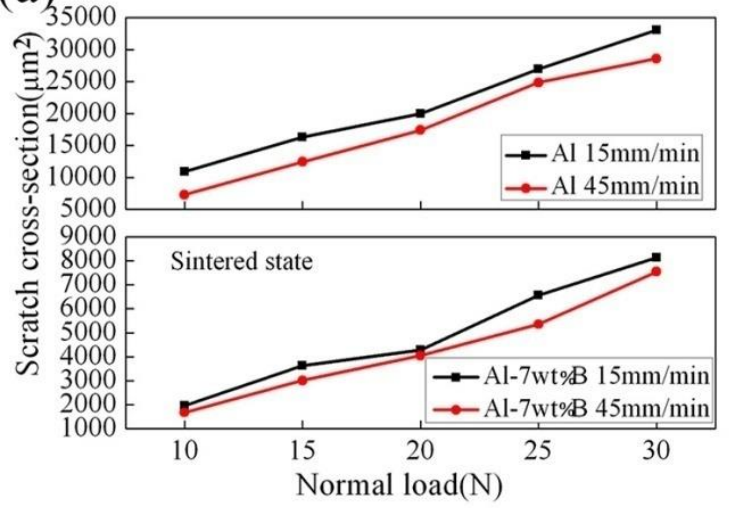

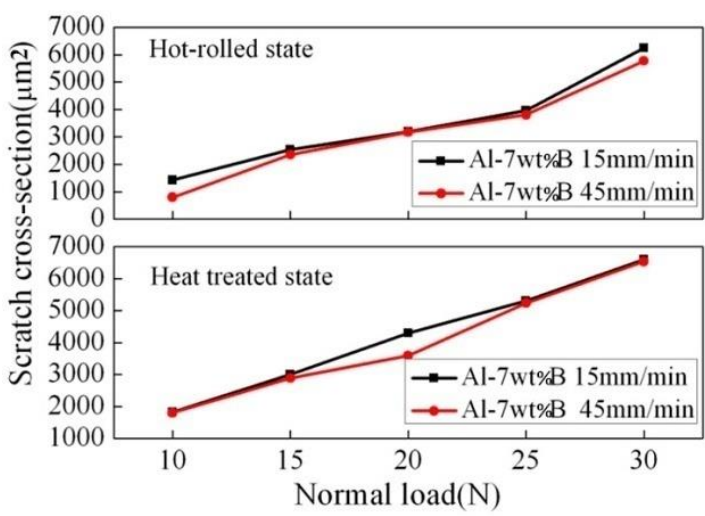


(b)
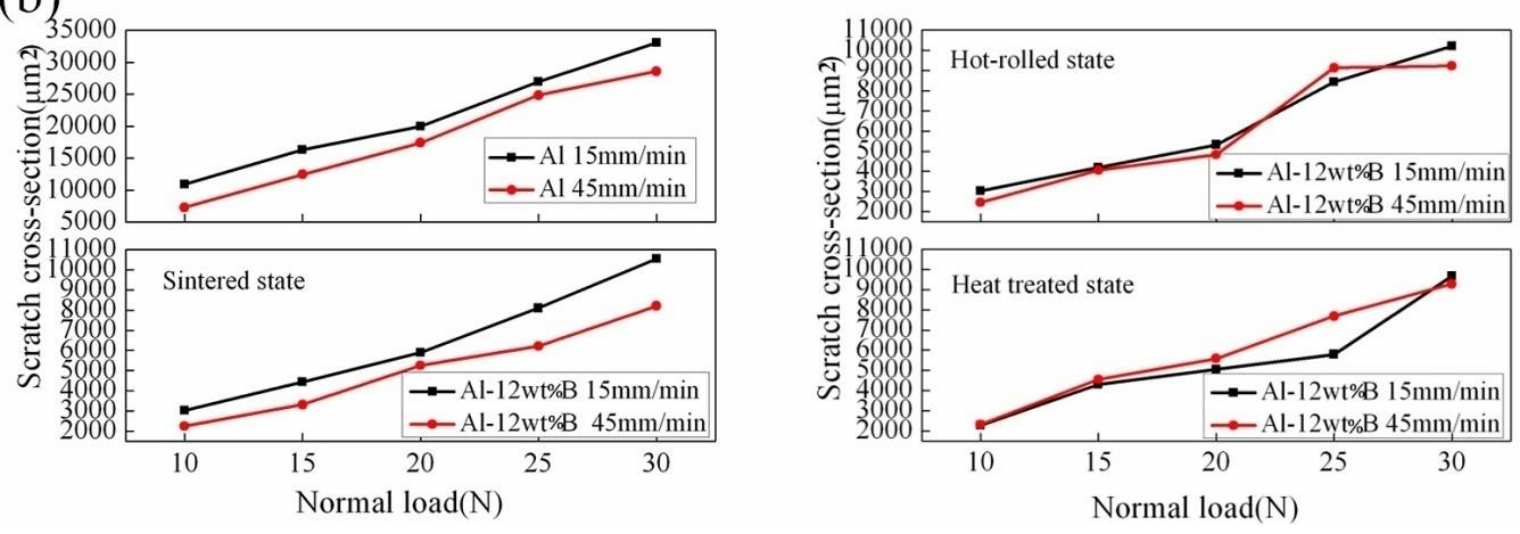

Fig. 6 Variation of scratch cross-section with normal load for all samples (a) Al-7wt\%B samples compared with $\mathrm{Al}$ and (b) Al-12wt\%B samples compared with Al.

As shown above, the hardness has some effect on the tribologicl behavior of the composites, but that is irregular. It is evident that the scratch cross-section tends to decrease during the increasing of the hardness for the Al-7wt\%B composites. But this effect is not obvious for the Al-12wt\%B composites.

It is clear from Fig. 6 that the unreinforced matrix materials worn much more than the reinforced composites, because the hard AIB2 particles (HKnoop=9.6GPa) effectively resist the micro-cutting of the indenter $[43,44]$. The scratch cross-sectional are as also increase linearly as the load increases for all materials. It is noted that $\mathrm{Al}-7 \mathrm{wt} \% \mathrm{~B}$ samples experience a smaller wear area than the $\mathrm{Al}-12 \mathrm{wt} \% \mathrm{~B}$ samples because of the higher wear resistance caused by the presence of more AlB2 particles. The wear area is basically lower at the speed of $45 \mathrm{~mm} / \mathrm{min}$ and this is consistent with previous research [30]. There is no evident relationship between the coefficient of friction and wear behavior.
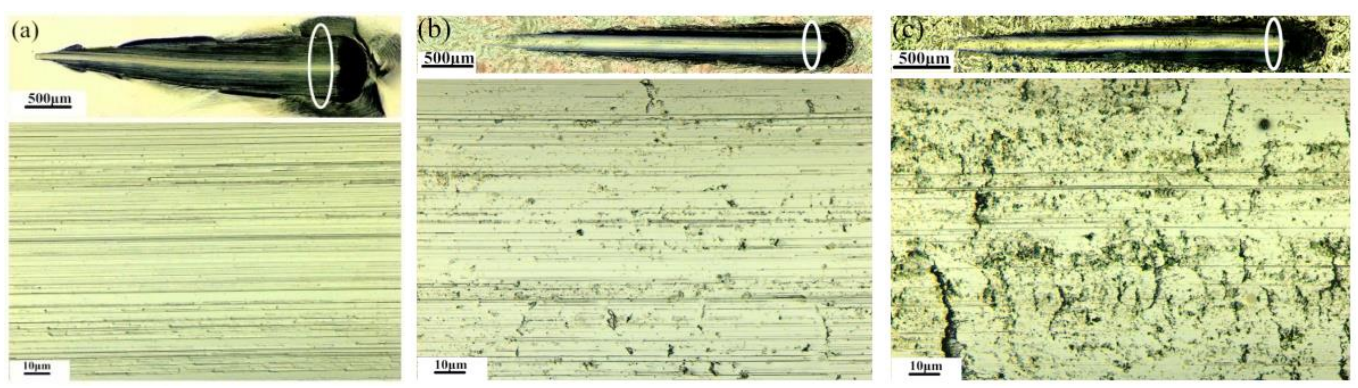

Fig. 7 Groove topography of matrix material and heat treated composites at a scratch speed of $45 \mathrm{~mm} / \mathrm{min}$ (a) Al, (b) Al-7wt\%B and (c) Al-12wt\%B.

Fig. 7 presents the groove topography of heat treated composites and Al at a scratch speed of $45 \mathrm{~mm} / \mathrm{min}$. It is obvious that the progressively increasing load accelerates the plastic deformation in the sliding direction in all cases. The groove shows a slight difference under different conditions. The smooth topography of the Al-7wt\%B composite in Fig. 7(b) is similar to that of pure $\mathrm{Al}$ (as shown in Fig. 7(a)), but the groove depth is shallower for theAl-7wt\%B composite. This is because AIB2 particles in the matrix change the stress state under the sliding conditions and influence wear behavior significantly. It can be seen that some fish-scales formed on the groove surface of the $\mathrm{Al}-12 \mathrm{wt} \% \mathrm{~B}$ specimen because of boron powder agglomeration. 
These loose areas have very low load-carrying capacity and hence are easily removed during scratch. In general, the scratch process is composed of rubbing, ploughing and plastic cutting [45]. For the composites studied in this work, some fractured particles could be observed on the groove surface.

\section{Conclusions}

The present study shows that:

(1) Aluminum matrix composites reinforced with in situ AlB2 particles were successfully fabricated by powder metallurgy followed by hot rolling.

(2) The microstructure and mechanical properties of composites deteriorate after excessive addition of boron powder in pure Al. This can be attributed primarily to the less uniform microstructures of $\mathrm{Al}-12 \mathrm{wt} \% \mathrm{~B}$ samples than those of $\mathrm{Al}-7 \mathrm{wt} \% \mathrm{~B}$.

(3) Under the present scratch test conditions, the wear resistance of the pure Al is improved significantly due to the formation of in situ AlB2 particles. The wear area and friction coefficient of the samples also increase almost linearly with the increase in the applied load.

(4) The sliding speed affects the coefficient of friction and wear in this study but no regular change is found.

\section{Acknowledgments}

The authors wish to gratefully acknowledge the help of Dr. Madeleine Strong Cincotta in the final language editing of this paper.The authors wish to gratefully acknowledge the help of Dr. Madeleine Strong Cincotta in the final language editing of this paper.The authors wish to gratefully acknowledge the help of Dr. Madeleine Strong Cincotta in the final language editing of this paper.The authors wish to gratefully acknowledge the help of Dr. Madeleine Strong Cincotta in the final language editing of this paper.

\section{References}

[1] Tjong SC, Ma ZY. Microstructural and mechanical characteristic of in situ metalmatrix composites. Mater Sci Eng R 2000;29:49-113.

[2] Tu JP, Rong W, Guo SY, Yang YZ. Dry sliding wear behavior of in situ Cu-TiB2 nano composites against medium carbon steel. Wear 2003;255:832-5.

[3] Donnell GO, Looney L. Production of aluminium matrix composite components using conventional PM technology. Mater Sci Eng A 2001; 303:292-301.

[4] Zhu HG, Ai YL, Min J, Wu Q, Wang HZ. Dry sliding wear behavior of Al-based composites fabricated by exothermic dispersion reaction in an Al-ZrO2-C system. Wear 2010; 268:1465-71.

[5] Ramnath BV, Elanchezhiana C, Jaivignesh M, et al. Evaluation of mechanical properties of aluminium alloy-alumina-boron carbide metal matrix composites. Mater Des 2014; $\underline{58: 332-8 .}$

[6] Zhang ZF, Zhang LC, Mai YW. Particle effects on friction and wear of aluminium matrix composites. J Mater Sci 1995; 30:5999-6004.

[7] Kumar S, Balasubramanian V. Effect of reinforcement size and volume fraction on the abrasive wear behavior of AA7075 Al/SiCp P/M composites-A statistical analysis. Tribol Int 2010;43:414422.

[8] Chen C, Guo L, Luo J, Hao J, Guo Z, Volinsky AA. Aluminum powder size and microstructure effects on properties of boron nitride reinforced aluminum matrix composites fabricated by 
semi-solid powder metallurgy. Mater Sci Eng A 2015;646:306-14.

[9] Suryanarayana C. Mechanical alloying and milling. Progress in Materials Science 2001:46; 1184.

[10] Khorshid MT, Jahromi SAJ, Moshksar MM. Mechanical properties of tri-modal Al matrix composites reinforced by nano-and submicron-sized Al2O3 particulates developed by wet attrition milling and hot extrusion. Materials and Design 2010;31:3880-4.

[11] Haghighi RD, Jahromi SAJ, Moresedgh A. A comparison between ECAP and conventional extrusion for consolidation of aluminum metal matrix composite. J Mater Eng Perform 2012;21:1885-92.

[12] Vajargah PH, Abdizadeh H, Baghchesara MA. Fabrication of TiB2 nanoparticulates reinforced aluminum matrix composites by powder metallurgy route. Journal of Composite Materials 2015;49(25):3115-25.

[13] Kerti I, Toptan F. Microstructural variations in cast B4C-reinforced aluminium matrix composites (AMCs). Mater Lett 2008;62:1215-8.

[14] Mazahery A, Shabani MO. Tribological behaviour of semisolid-semisolid compocast Al-Si matrix composites reinforced with TiB2 coated B4C particulates. Ceram Int 2012;38:1887-95.

[15] Kubota M, Cizek P. Synthesis of Al3BC from mechanically milled and spark plasma sintered Al-MgB2 composite materials. J Alloy Compd 2008;457:209-15.

[16] Ağaoğulları D, Gökçe H, Duman I , Lütfi Öveçoğlu M. Aluminum diboride systhesis from elemental powders by mechanical alloying and annealing. J Eur Ceram Soc 2012;32:1457-62.

[17] Toptan F, Kilicarslan A, Karaaslan A, Cigdem M, Kerti I. Processing and microstructural characterisation of AA 1070 and AA 6063 matrix B4Cp reinforced composites. Mater Design 2010;31:S87-S91.

[18] Topcua I, Gulsoy HO, Kadioglu N, Gulluoglu AN. Processing and mechanical properties of B4C reinforced Al matrix composites. J Alloy Compd 2009;482:516-521.

[19] Kubota M. Solid-state reaction in mechanically milled and spark plasma sintered Al-B4C composite materials. J Alloy Compd 2010;504S:S319-S322.

[20] Shabani MO, Mazahery A. Modeling of the wear behavior in A356-B4C composites. J Mater Sci 2011; 46:6700-8.

[21] Gangolu S, Rao AG, Prabhu N, Deshmukh VP, Kashyap BP. Hot Workability and Flow Characteristics of Aluminum-5 wt.\% B4C Composite. J Mater Eng Perform 2014;23(4):1366-73.

[22] Soy U, Demir A, Findik F. Friction and wear behaviors of Al-SiC-B4C composites produced by pressure infiltration method. Ind Lubr Tribol 2011;63(5):387-393.

[23] Mazahery A, Shabani MO. Mechanical Properties of Squeeze-Cast A356 Composites Reinforced With B4C Particulates. J Mater Eng Perform 2012;21:247-52.

[24] Kang PC, Cao ZW, Wu GH, Zhang JH, Wei DJ, Lin LT. Phase identification of Al-B4C ceramic composites synthesized by reaction hot-press sintering. Int J Refract Met H 2010;28:297-300.

[25] Vogt RG, Zhang Z, Topping TD, Lavernia EJ, Schoenung JM. Cryomilled aluminum alloy and boron carbide nano-composite plate. J Mater Process Tech 2009;209:5046-53.

[26] Khakbiz M, Akhlaghi F. Synthesis and structural characterization of Al-B4C nano-composite powders by mechanical alloying. J Alloy Compd 2009;479:334-41.

[27] Onoro J, Salvador MD, Cambronero LEG. High-temperature mechanical properties of aluminium alloys reinforced with boron carbide particles. Mater Sci Eng A 2009;499:421-6.

[28] Kayikci R, Savas Ö, Koksal S, Demir A. The effect of reinforcement ratio on the wear 
behavioour of AlB2 flake reinforced metal matrix composites. Acta phys pol A 2014;125:590-2.

[29] Savaş Ö, Kayikci R. Production and wear properties of metal matrix composites reinforced with boride particles. Mater. Des. 2013; 51:641-7.

[30] Koksal S, Ficici F, Kayikci R, Savaş Ö. Experimental optimization of dry sliding wear behavior of in situ AlB2/Al composite based on Taguchi's method. Mater Des 2012;42:124-30.

[31] Ficici F, Koksal S, Kayikci R. Investigation of unlubricated sliding wear behaviours of in-situ AlB2/Al metal matrix composite. Adv Compos Lett 2011;20:109-16.

[32] Sigworth GK, Kuhn TA. Grain Refinement of aluminium casting alloys. AFS Tran 2007;115:112.

[33] Roy MN, Sinha A. Viscous synergy and antagonism and isentropic compressibility of ternary mixtures containing 1,3-dioxolane, water and monoalkanols at 303.15K. Fluid Phase Equilibr 2006;243:133-41.

[34] Gan Y, Lim YS, Qiao L. Combustion of nanofluid fuels with the addition of boron and iron particles at dilute and dense concentrations. Combust Flame 2012;159:1732-40.

[35] Guo L, Song W, Xie C, Zhang X, Hu M. Characterization and thermal properties of carbon-coated aluminum nanopowders prepared by laser-induction complex heating in methane. Mater Lett 2007;61:3211-4.

[36] Kontoyannis CG, Vagenas NV. Calcium caronate phase analysis using XRD and FT-Raman spectroscopy. Analyst 2000;125:251-5.

[37] Tjong SC, Lau KC. Properties and abrasive wear of TiB2/Al-4\%Cu composites produced by hot isostatic pressing. Compos Sci Technol 1999;59:2005-13.

[38] Rezayat M, Akbarzadeh A. Fabrication of aluminium matrix composites reinforced by submicrometre and nanosize Al2O3 via accumulative roll bonding. Mater Sci Technol 2012;28:1233-40.

[39] Kwon H, Estili M, Takagi K, Miyazaki T, Kawasaki A. Combination of hot extrusion and spark plasma sintering for producing carbon nano tube reinforced aluminum matrix composites. Carbon 2009; 47:570-7.

[40] Wei W, Wei KX, Fan GJ. A new constitutive equation for strain hardening and softening offcc metals during severe plastic deformation. Acta Mater 2008;56:4771-9.

[41] Rohatgi A, Vecchio KS, Gray III GT. The influence of stacking fault energy on the mechanical behavior of $\mathrm{Cu}$ and $\mathrm{Cu}-\mathrm{Al}$ Alloys: Deformation twinning, work hardening, and dynamic recovery. Metall Mater Trans A 2001; 32:135-45.

[42] Sigworth GK. The grain refining of aluminum and phase relationships in the Al-Ti-B system metall. Mater Trans A 1984;15:277-82.

[43] Kök M, Özdin K. Wear resistance of aluminium alloy and its composites reinforced by Al2O3 particles. Mater Process Technol 2007;183:301-9.

[44] Duschanek H, Roagl P. The Al-B (Aluminum-Boron) System. J Phase Equilib Diff 1994, 15(5): $543-552$.

[45] Yan C, Zhang L. Single-point scratching of 6061 Al alloy reinforced by different ceramic particles. Appl Compos Mater 1994;1:431-47. 